\title{
Terahertz Time Domain, Raman and Fourier Transform Infrared Spectroscopy of Acrylamide, and the Application of Density Functional Theory
}

\author{
Ramzan Ullah, ${ }^{1}$ Salah Ud-Din Khan, ${ }^{2}$ Muhammad Aamir, ${ }^{3}$ and Rasheed Ullah ${ }^{4}$ \\ ${ }^{1}$ School of Optical-Electrical and Computer Engineering, University of Shanghai for Science \& Technology, Shanghai 200093, China \\ ${ }^{2}$ King Saud University, P.O. Box 800, Riyadh 11421, Saudi Arabia \\ ${ }^{3}$ Institute of Thermo Physics, School of Power Engineering, Chongqing University, Chongqing 400044, China \\ ${ }^{4}$ Department of Computer and Software Engineering, Bahria University, Islamabad 44000, Pakistan
}

Correspondence should be addressed to Ramzan Ullah; ramzanullah@gmail.com

Received 29 August 2013; Revised 14 October 2013; Accepted 15 October 2013

Academic Editor: D. Sajan

Copyright (c) 2013 Ramzan Ullah et al. This is an open access article distributed under the Creative Commons Attribution License, which permits unrestricted use, distribution, and reproduction in any medium, provided the original work is properly cited.

We present terahertz time domain spectra of acrylamide in the frequency range from 0.2 to $2 \mathrm{THz}$ with nearly constant refractive index having an average value of 1.33 and an absorption coefficient. Raman $\left(95-3000 \mathrm{~cm}^{-1}\right)$ and FTIR $\left(450-4000 \mathrm{~cm}^{-1}\right) \mathrm{spectra}$ also show good agreement with density functional theory (DFT) B3LYP 6-311G++ (3df 3pd) calculations except C-H and N-H stretching frequencies even after scaling with scale factor of 0.9679 . We use MOLVIB to rescale such frequencies to match experimental values.

\section{Introduction}

A strip between the microwave and infrared region of electromagnetic spectrum is named terahertz band spanning from 0.1 to $10 \mathrm{THz}$ [1]. Terahertz time domain transmission spectroscopy has been applied tremendously in the fields of materials characterization [2-5], defense and security [6-11], telecommunication [12], and biomedical sciences.

Acrylamide $\left(\mathrm{C}_{3} \mathrm{H}_{5} \mathrm{NO}\right)$ is a heat generated toxicant found mostly in starchy foods cooked or processed at high temperature and may be a possible carcinogen according to the World Health Organization (WHO) [13]. Moreover, high intake of acrylamide increases the risk of endometrial cancer and possibly ovarian cancer in women [14]. This alarming situation demands an immediate and indepth exploration of acrylamide, and the most challenging task in this regard is to detect the acrylamide in foods in all forms accurately and efficiently. Acrylamide is the primary component of polymers and polyacrylamides out of which the latter is not only being used in genetic and biological laboratories as gel electrophoresis but also as flocculator and soil-conditioning agent in other fields. Molecular structure of acrylamide is shown in Figure 1.

\section{Experimental Setup}

Ultrafast Fiber Laser System (Near-Infrared System FemtoFiber Pro NIR from TOPTICA Photonics) [15] is used to generate subpicosecond $\mathrm{THz}$ pulses. Wavelength of the laser is set to $780 \mathrm{~nm}$ with an average power of greater than $140 \mathrm{~mW}$. Pulse width is less than $100 \mathrm{fs}$ and repetition rate is $80 \mathrm{MHz}$. Our THz setup is THz Time-Domain Spectroscopy System with fast scanning (EKSPLA) [16]. A schematic diagram of our setup is shown in Figure 2. Beam splitter 1 (BS1) splits the laser beam in ratio $80: 20$ to reduce the optical power. Beam Splitter 2 (BS2) divides the laser beam into pump and probe beam. Split ratio is $50: 50$ by adjusting the half wave plate. Our THz emitter and detector is LTGGaAs photoconductive switch. THz emitter is biased at $50 \mathrm{~V}$ and $\mathrm{Si}$ lens is mounted on the back of emitter and detector for enhanced collimation. Probe laser pulse hits the $\mathrm{THz}$ emitter after passing through the focusing lens L1 which focuses it to the gap of photoconductive antenna. THz signal is guided towards the sample and then to the detector by four off axis parabolic mirrors. Fast delay line is used to acquire the signal in real time while slow delay line is used to adjust the pump and probe laser beams temporally. It has 


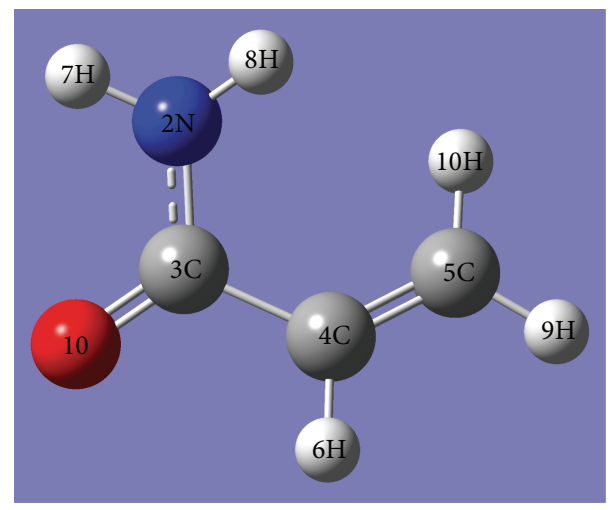

Figure 1: Acrylamide molecule.

an optional advantage to increase the resolution. $\mathrm{THz}$ signal is detected by digital signal processor built in a central controller which is connected with slow delay line, fast delay line, and $\mathrm{THz}$ emitter while detector is connected via operational preamplifier. Central controller displays the $\mathrm{THz}$ signal on personal computer in time domain. Average of 1024 signals was taken for each measurement to get a very high signal to noise ratio of more than $10^{5}: 1$. The whole setup is inside a box whose relative humidity was dropped below $5 \%$ by nonheating sorbent dryer, and temperature was maintained at $23^{\circ} \mathrm{C}$. THz system is shown in Figure 2. RamanStation $400 \mathrm{~F}$ [17] and Spectrum 100 FTIR [18, 19] from PerkinElmer are used for Raman and FTIR spectroscopy, respectively.

\section{Sample Preparation}

"Acrylamide" CAS no. [79-06-1] powder is bought from "Sinopharm Chemical Reagent Co. Ltd" [20] and is ground to very fine powder. This powder is then pressed homogeneously between two plates of polystyrene and sealed from the sides. Refractive index and absorption coefficient of polystyrene are determined first with air as reference. Equation (14) was used for refractive index and (15) for absorption coefficient by setting $n_{p}=1$. A constant refractive index of 1.58 and nearly zero absorption coefficient of polystyrene $(0.2-2 \mathrm{THz})$ are calculated which is consistent with the literature [21]. Thickness is determined by a digital micrometer capable of measuring the thickness up to $0.001 \mathrm{~mm}$ precision. Many samples are prepared with varying thicknesses with one reference. Reference cell is prepared by joining two polystyrene plates as shown in Figure 3.

\section{Data Analysis}

We derive the formulae for refractive index and absorption coefficient as follows. We know that absorption coefficient $\alpha$ and phase $\varphi$ can be represented as

$$
\begin{gathered}
\alpha_{1}=\frac{2 n_{1(\mathrm{Im})} \omega}{c}, \\
\varphi_{1}=\frac{\omega d \tilde{n}_{1}}{c},
\end{gathered}
$$

where $n_{1(\mathrm{Im})}$ is the imaginary part and $\tilde{n}_{1}$ is the complex refractive index of the material under consideration, $\omega$ is angular frequency, $d$ is the sample thickness, and $c$ is speed of light whose value is taken as $299792458 \mathrm{~m} / \mathrm{s}$.

We represent the electric fields as follows:

$$
\begin{array}{r}
E_{\text {reference }}(\omega)=\left(t_{A P} e^{i \varphi_{p}}\right)\left(e^{i \varphi_{r}}\right)\left(e^{i \varphi_{p}}\right)\left(t_{P A}\right) E(\omega), \\
E_{\text {sample }}(\omega)=\left(t_{A P} e^{i \varphi_{p}}\right)\left(t_{P S} e^{i \varphi_{s}}\right)\left(t_{S P} e^{i \varphi_{p}}\right)\left(t_{P A}\right) E(\omega) .
\end{array}
$$

Here, $t$ represents the complex transmission Fresnel's coefficients with subscripts being the interface of two media and $\varphi$ is the phase accumulated while passing through the media. $\varphi_{r}$ is the phase accumulated while passing through the air through a distance equal to the sample width where the value of $\varphi$ can be determined using (2). $E(\omega)$ is the incident electric field:

$$
t_{A B}=\frac{2 \widetilde{n}_{B}}{\widetilde{n}_{A}+\widetilde{n}_{B}}
$$

where $A$ and $B$ are representing two media and $A B$ is the interface of two media. Dividing (4) by (3),

$$
\begin{gathered}
\frac{E_{\text {sample }}(\omega)}{E_{\text {reference }}(\omega)}=\frac{\left(t_{A P} e^{i \varphi_{p}}\right)\left(t_{P S} e^{i \varphi_{s}}\right)\left(t_{S P} e^{i \varphi_{p}}\right)\left(t_{P A}\right) E(\omega)}{\left(t_{A P} e^{i \varphi_{p}}\right)\left(e^{i \varphi_{r}}\right)\left(e^{i \varphi_{p}}\right)\left(t_{P A}\right) E(\omega)}, \\
\frac{E_{\text {sample }}(\omega)}{E_{\text {reference }}(\omega)}=t_{P S} t_{S P} e^{i\left(\varphi_{s}-\varphi_{r}\right)} .
\end{gathered}
$$

Putting the values of $\varphi_{s}$ and $\varphi_{r}$ using (2) and adding appropriate subscripts,

$$
\frac{E_{\text {sample }}(\omega)}{E_{\text {reference }}(\omega)}=t_{P S} t_{S P} e^{i\left[\omega d \widetilde{n}_{\text {sample }} / c-\omega d \widetilde{n}_{\text {air }} / c\right]}
$$

As we assume that there is no absorption in air, so

$$
\begin{gathered}
\tilde{n}_{\text {air }}=n_{\text {air }}=1, \\
\frac{E_{\text {sample }}(\omega)}{E_{\text {reference }}(\omega)}=t_{P S} t_{S P} e^{i\left[\omega d \tilde{n}_{\text {sample }} / c-\omega d / c\right]},
\end{gathered}
$$

$$
\frac{E_{\text {sample }}(\omega)}{E_{\text {reference }}(\omega)}=t_{P S} t_{S P} e^{i(\omega d / c)\left[\left(n_{\text {sample(Re })}+i n_{\text {sample(Im })}\right)-1\right]}
$$

$$
\frac{E_{\text {sample }}(\omega)}{E_{\text {reference }}(\omega)}=t_{P S} t_{S P} e^{i(\omega d / c)\left[\left(n_{\text {sample(Re })}-1\right)\right]+i(\omega d / c)\left[i\left(n_{\text {sample(Im) })}\right)\right]}
$$

$$
\frac{E_{\text {sample }}(\omega)}{E_{\text {reference }}(\omega)}=t_{P S} t_{S P} e^{i(\omega d / c)\left[\left(n_{\text {sample(Re) })}-1\right)\right]} e^{-(\omega d / c)\left[n_{\text {sample(Im) })}\right.} \text {. }
$$




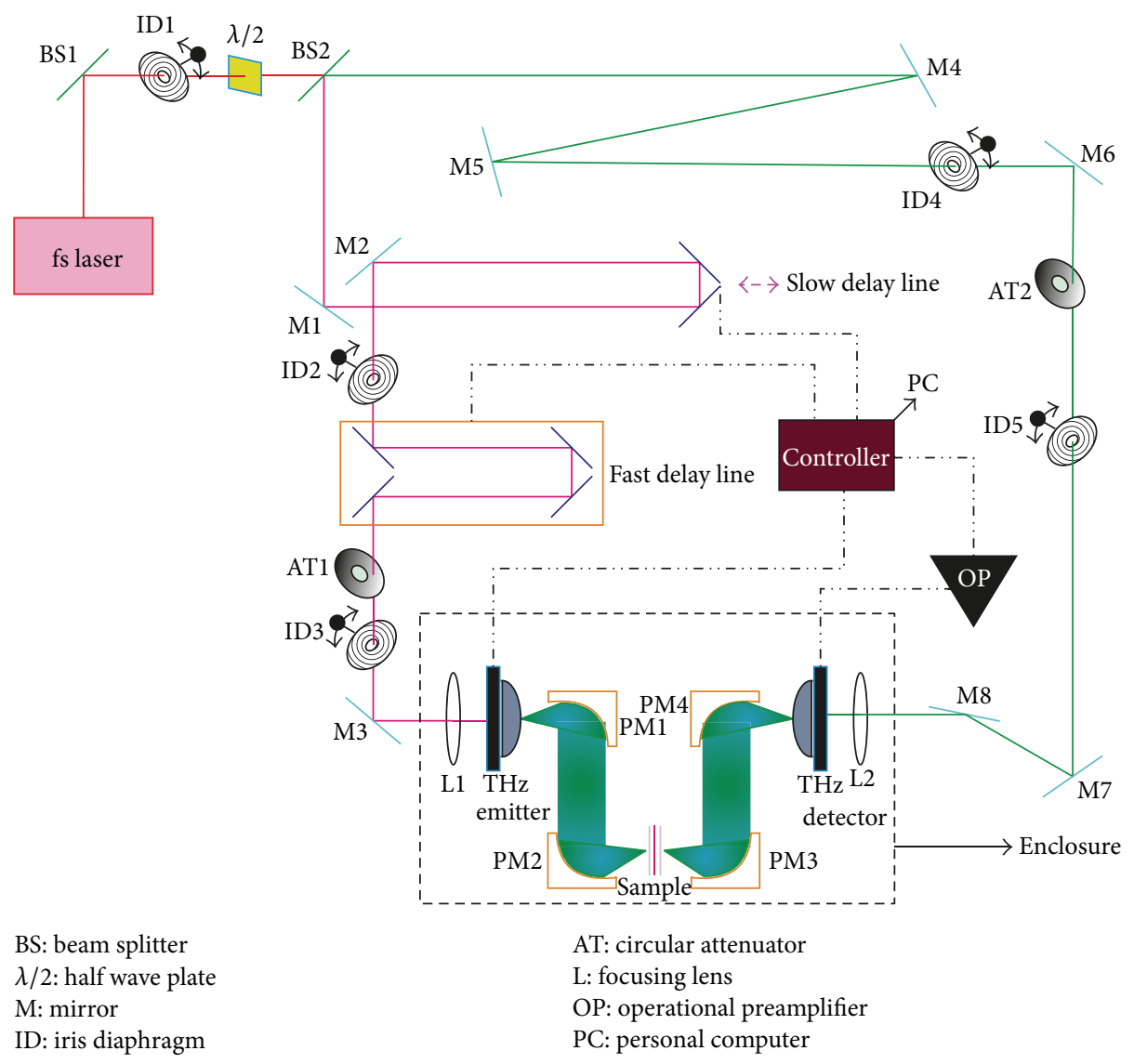

FIGURE 2: Complete THz setup.

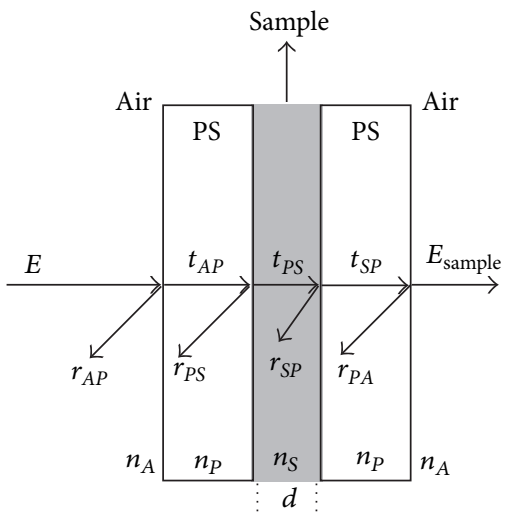

(a)

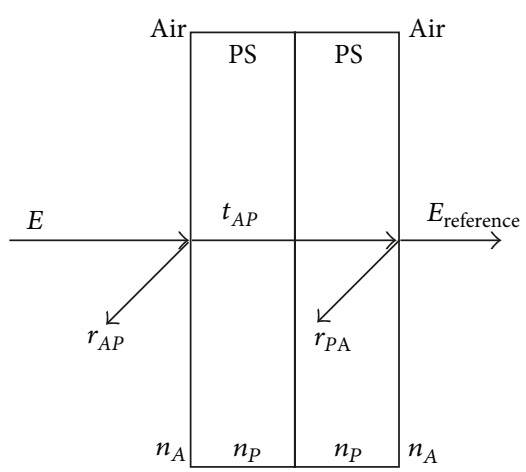

(b)

FIGURE 3: (a) Sample cell layout along with Fresnel's reflections $(r)$ and transmissions $(t)$ coefficients where subscripts represent the interface of two media. $E$ is the electric field, $n$ represents the refractive index of the medium, and subscripts here represent the medium. $d$ is the thickness of the sample. (b) Reference cell layout where the two polystyrene (PS) plates are joined with each other without any space in between. Reflections are rotated for clarity in both cases. All the reflections are normal to the interface but opposite in direction to transmission rays.

As $n_{\text {sample(Im) }}$ is related to absorption coefficient " $\alpha$ ", so by using (1) and adding appropriate subscripts,

$$
\frac{E_{\text {sample }}(\omega)}{E_{\text {reference }}(\omega)}=t_{P S} t_{S P} e^{-\alpha_{\text {sample }} \mathrm{d} / 2} e^{i(\omega d / c)\left[\left(n_{\text {sample }}-1\right)\right]} .
$$

Entering the values of $t_{P S}$ and $t_{S P}$ by using (5),

$$
\begin{aligned}
& \frac{E_{\text {sample }}(\omega)}{E_{\text {reference }}(\omega)} \\
& =\left[\frac{2 \widetilde{n}_{P}}{\widetilde{n}_{P}+\widetilde{n}_{\text {sample }}}\right]\left[\frac{2 \widetilde{n}_{\text {sample }}}{\widetilde{n}_{\text {sample }}+\widetilde{n}_{P}}\right] e^{-\alpha_{\text {sample }} \mathrm{d} / 2} e^{i(\omega d / c)\left[\left(n_{\text {sample }}-1\right)\right]} .
\end{aligned}
$$



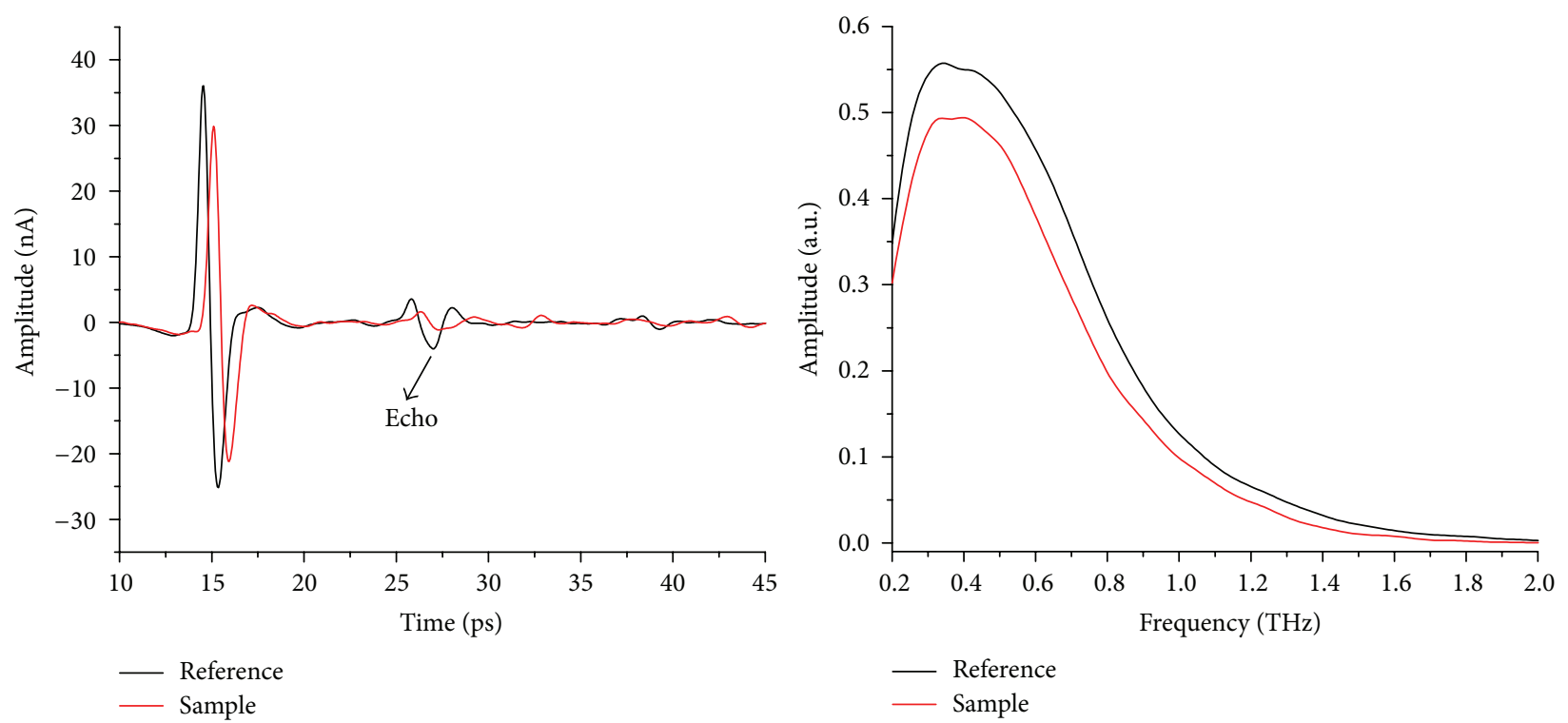

FIGURE 4: Time domain traces of reference which is two PS plates together without any space in between and sample which is "Acrylamide" pressed between two PS plates and their FFTs.

As polystyrene (PS) has no absorption and for the sample, we also assume that absorption is negligible. So,

$$
\begin{gathered}
\tilde{n}_{\text {sample }}=n_{\text {sample }}, \quad \tilde{n}_{P}=n_{P}, \\
\frac{E_{\text {sample }}(\omega)}{E_{\text {reference }}(\omega)} \\
=\left[\frac{4 n_{P} n_{\text {sample }}}{\left(n_{P}+n_{\text {sample }}\right)^{2}}\right] e^{-\alpha_{\text {sample }} \mathrm{d} / 2} e^{i(\omega d / c)\left[\left(n_{\text {sample }}-1\right)\right]} .
\end{gathered}
$$

Comparing the above result with Euler's form of the equation,

$$
\begin{gathered}
\frac{A_{\text {sample }}}{A_{\text {reference }}} e^{i\left(\varphi_{S}-\varphi_{R}\right)} \\
=\left[\frac{4 n_{P} n_{\text {sample }}}{\left(n_{P}+n_{\text {sample }}\right)^{2}}\right] e^{-\alpha_{\text {sample }} \mathrm{d} / 2} e^{i(\omega d / c)\left[\left(n_{\text {sample }}-1\right)\right]}, \\
\frac{A_{\text {sample }}}{A_{\text {reference }}}=\left[\frac{4 n_{P} n_{\text {sample }}}{\left(n_{P}+n_{\text {sample }}\right)^{2}}\right] e^{-\alpha_{\text {sample }} \mathrm{d} / 2}, \\
\varphi_{S}-\varphi_{R}=\frac{\omega d}{c}\left[\left(n_{\text {sample }}-1\right)\right] .
\end{gathered}
$$

We can evaluate the values of $\alpha$ and $n_{\text {sample }}$ from (13):

$$
\begin{gathered}
n_{\text {sample }}=1+\left(\varphi_{S}-\varphi_{R}\right) \frac{c}{\omega d}, \\
\alpha_{\text {sample }}=-\frac{2}{d} \ln \left[\frac{A_{\text {sample }}}{A_{\text {reference }}} \times \frac{\left(n_{P}+n_{\text {sample }}\right)^{2}}{4 n_{P} n_{\text {sample }}}\right] .
\end{gathered}
$$

Sample amplitude $A_{\text {sample}}$, reference amplitude $A_{\text {reference }}$, sample phase $\varphi_{S}$, and reference phase $\varphi_{R}$ are put from experimental data after performing fast Fourier transform (FFT) on time domain traces in the previous formulae. $\omega$ is angular frequency, $c$ is speed of light, $d$ is sample thickness, and $n_{p}$ is the refractive index of polystyrene whose value was taken as 1.58. Error bars are showing 95\% confidence interval calculated from the standard error of the mean. Error bars are almost constant for the refractive index until $1.8 \mathrm{THz}$ and minimum for absorption coefficient in the range 0.2 to 1.2 THz. Error bars are large in the high frequency range because of low signal to noise ratio caused by weak input signal and large absorption in high frequency region. Time domain reference and sample pulses along with their FFTs are shown in Figure 4. Terahertz time domain signals were padded with zeros from 21 ps before performing FFT.

\section{DFT Calculations}

DFT calculations are carried out in Gaussian 09 package [22] with Ground State method B3LYP along with 6-311G basis set [23] together with (3df, $3 \mathrm{pd}$ ) and ++ diffuse functions [24]. Raman activities are calculated at incidence frequency of $785 \mathrm{~nm}$ which is the frequency of excitation source of our Raman spectrometer [17]. Optimization and frequency calculations are done, and vibrational spectra are compared with experimental results. On the basis of these DFT calculations, experimental peaks are assigned to relevant molecular vibrations. List of all modes along with FTIR, Raman, and potential energy distribution (PED) analysis is given in Table 1 .

\section{Results and Discussion}

As shown in Figure 5, refractive index of acrylamide is almost constant from 0.2 to $2 \mathrm{THz}$ with an average value of 1.33 , and 
TABLE 1: List of all DFT intramolecular vibrational modes along with assignment with FTIR, Raman, and PED.

\begin{tabular}{|c|c|c|c|c|}
\hline S. no. & $\operatorname{DFT}\left(\mathrm{cm}^{-1}\right)$ & $\begin{array}{l}\text { FTIR } \\
\left(\mathrm{cm}^{-1}\right)\end{array}$ & $\begin{array}{l}\text { Raman } \\
\left(\mathrm{cm}^{-1}\right)\end{array}$ & $\begin{array}{l}\text { PED (\%) most } \\
\text { significant } \\
\text { normalized PED }\end{array}$ \\
\hline 1 & $\begin{array}{c}(92.94)_{\text {Unscaled }} \\
(87.1)_{\text {Scaled }}\end{array}$ & - & - & $\begin{array}{l}\text { CCt (76), } \\
\text { CHob (10) }\end{array}$ \\
\hline 2 & $\begin{array}{c}(275.05)_{\text {Unscaled }} \\
(285.3)_{\text {Scaled }}\end{array}$ & - & 307 & $\begin{array}{l}\text { CNob (49), } \\
\text { CNH (20), } \\
\text { CNt (8), } \\
\text { CCC (7) }\end{array}$ \\
\hline 3 & $\begin{array}{c}(330.08)_{\text {Unscaled }} \\
(327.8)_{\text {Scaled }}\end{array}$ & - & Absent & $\begin{array}{l}\text { CNob (62), } \\
\text { CNH (26) }\end{array}$ \\
\hline 4 & $\begin{array}{l}(431.60)_{\text {Unscaled }} \\
\quad(430.1)_{\text {Scaled }}\end{array}$ & - & Absent & $\begin{array}{l}\text { COob (30), } \\
\text { CHob (21), } \\
\text { CCt (18), } \\
\text { CNt (10) }\end{array}$ \\
\hline 5 & $\begin{array}{c}(527.19)_{\text {Unscaled }} \\
(532.0)_{\text {Scaled }}\end{array}$ & 508 & 509 & $\begin{array}{l}\text { CNt (55), } \\
\text { CC (12), } \\
\text { CCO (9), } \\
\text { NCO (6), } \\
\text { CNH (6), } \\
\text { CNob (5) }\end{array}$ \\
\hline 6 & $\begin{array}{c}(559.39)_{\text {Unscaled }} \\
(569.4)_{\text {Scaled }}\end{array}$ & 623 & 615 & $\begin{array}{c}\mathrm{CNt}(25), \\
\mathrm{NCO}(20), \\
\mathrm{CC}(14), \\
\mathrm{CNH}(13), \\
\text { CCO (8) }\end{array}$ \\
\hline 7 & $\begin{array}{c}(590.55)_{\text {Unscaled }} \\
\quad(597.3)_{\text {Scaled }}\end{array}$ & 661 & Absent & $\begin{array}{c}\text { CNH (22), } \\
\text { NCC (18), } \\
\text { CCH (10), } \\
\text { CCC (9), } \\
\text { CHob (8), } \\
\text { CCt (8) }\end{array}$ \\
\hline 8 & $\begin{array}{c}(819.3)_{\text {Unscaled }} \\
(798.8)_{\text {Scaled }}\end{array}$ & 817 & 812 & $\begin{array}{c}\mathrm{CC}(42), \\
\mathrm{CN}(22), \\
\mathrm{CNH}(12), \\
\mathrm{CCH}(8)\end{array}$ \\
\hline 9 & $\begin{array}{l}(823.28)_{\text {Unscaled }} \\
\quad(811.4)_{\text {Scaled }}\end{array}$ & 840 & 845 & $\begin{array}{l}\text { COob (57), } \\
\text { CCt (17), } \\
\text { CHob (12) }\end{array}$ \\
\hline 10 & $\begin{array}{l}(986.46)_{\text {Unscaled }} \\
\quad(976.7)_{\text {Scaled }}\end{array}$ & 962 & 959 & CCob (97) \\
\hline 11 & $\begin{array}{l}(1038.56)_{\text {Unscaled }} \\
(1006.5)_{\text {Scaled }}\end{array}$ & 989 & 1050 & $\begin{array}{l}\text { CCt (53), } \\
\text { CHob (43) }\end{array}$ \\
\hline 12 & $\begin{array}{c}(1043.85)_{\text {Unscaled }} \\
(1029.7)_{\text {Scaled }}\end{array}$ & 1051 & 1053 & $\begin{array}{l}\mathrm{CCH}(43), \\
\mathrm{CN}(31), \\
\mathrm{CNH}(20)\end{array}$ \\
\hline 13 & $\begin{array}{c}(1113.69)_{\text {Unscaled }} \\
\quad(1132.6)_{\text {Scaled }}\end{array}$ & 1137 & 1145 & $\begin{array}{c}\mathrm{CNH}(70), \\
\mathrm{CCH}(10), \\
\mathrm{CO}(9)\end{array}$ \\
\hline 14 & $\begin{array}{c}(1310.66)_{\text {Unscaled }} \\
(1297.2)_{\text {Scaled }}\end{array}$ & 1280 & 1283 & $\begin{array}{c}\mathrm{CCH}(72), \\
\mathrm{CC}(20)\end{array}$ \\
\hline 15 & $\begin{array}{c}(1359.85)_{\text {Unscaled }} \\
\quad(1351.1)_{\text {Scaled }}\end{array}$ & 1352 & Absent & $\begin{array}{c}\mathrm{CN}(31), \\
\mathrm{CNH}(28), \\
\mathrm{CC}(16), \\
\mathrm{NCO}(9), \\
\mathrm{CCO}(7), \\
\mathrm{CCH}(6)\end{array}$ \\
\hline
\end{tabular}

TABle 1: Continued.

\begin{tabular}{|c|c|c|c|c|}
\hline S. no. & $\operatorname{DFT}\left(\mathrm{cm}^{-1}\right)$ & $\begin{array}{l}\text { FTIR } \\
\left(\mathrm{cm}^{-1}\right)\end{array}$ & $\begin{array}{l}\text { Raman } \\
\left(\mathrm{cm}^{-1}\right)\end{array}$ & $\begin{array}{c}\text { PED (\%) most } \\
\text { significant } \\
\text { normalized PED }\end{array}$ \\
\hline 16 & $\begin{array}{c}(1455.77)_{\text {Unscaled }} \\
(1430.8)_{\text {Scaled }}\end{array}$ & 1429 & 1432 & $\begin{array}{c}\mathrm{HCH}(35), \\
\mathrm{CCH}(33), \\
\mathrm{CC}(26)\end{array}$ \\
\hline 17 & $\begin{array}{c}(1618.2)_{\text {Unscaled }} \\
(1603.9)_{\text {Scaled }}\end{array}$ & 1614 & 1587 & $\begin{array}{l}\text { CC (55), } \\
\text { CO (17), } \\
\mathrm{HCH}(13), \\
\text { CCH (11) }\end{array}$ \\
\hline 18 & $\begin{array}{c}(1681.96)_{\text {Unscaled }} \\
(1634.6)_{\text {Scaled }}\end{array}$ & Absent & 1636 & $\begin{array}{l}\mathrm{CNH}(62), \\
\mathrm{CO}(17), \\
\text { CC (13) }\end{array}$ \\
\hline 19 & $\begin{array}{c}(1750.54)_{\text {Unscaled }} \\
(1679.0)_{\text {Scaled }}\end{array}$ & 1674 & 1680 & $\begin{array}{c}\mathrm{CO}(51), \\
\mathrm{CNH}(22), \\
\mathrm{CC}(9), \\
\mathrm{CN}(9)\end{array}$ \\
\hline 20 & $\begin{array}{c}(3139.86)_{\text {Unscaled }} \\
(2941.7)_{\text {Scaled }}\end{array}$ & 2813 & Absent & CH (99) \\
\hline 21 & $\begin{array}{c}(3182.91)_{\text {Unscaled }} \\
(2980.8)_{\text {Scaled }}\end{array}$ & 3034 & - & CH (99) \\
\hline 22 & $\begin{array}{l}(3222.77)_{\text {Unscaled }} \\
(3017.6)_{\text {Scaled }}\end{array}$ & 3102 & - & $\mathrm{CH}(100)$ \\
\hline 23 & $\begin{array}{c}(3588.71)_{\text {Unscaled }} \\
(3210.5)_{\text {Scaled }}\end{array}$ & 3191 & - & NH (100) \\
\hline 24 & $\begin{array}{c}(3716.11)_{\text {Unscaled }} \\
(3327.7)_{\text {Scaled }}\end{array}$ & 3347 & - & NH (100) \\
\hline
\end{tabular}

Ob: out of plane bending, t: torsion, Unscaled: raw DFT values without any scaling, Scaled: scaled with MOLVIB.

Note: animation of all of these vibrational modes can be found in the Supplementary Material available online at http://dx.doi.org/10.1155/2013/148903.

absorption coefficient is also constant in $0.2-1.2 \mathrm{THz}$ range after which it slowly starts rising up without any significant peak in this region. This agrees well with DFT calculation which predicts no intramolecular vibrational mode in this range. According to DFT calculations, first vibrational mode appears at $2.786 \mathrm{THz}\left(92.94 \mathrm{~cm}^{-1}\right.$ Unscaled in Table 1$)$ which is obviously beyond the range of our $\mathrm{THz}$ spectrometer. Spectra of both FTIR and DFT are shown in Figure 6. As 3100 to $3000 \mathrm{~cm}^{-1}$ region is characterized by carbon-hydrogen (C-H) stretching [25], hence, the peaks at 2813 and 3034 and $3102 \mathrm{~cm}^{-1}$ are assigned to $\mathrm{C}-\mathrm{H}$ stretching as shown in Figure 6. Two absorption lines at 3191 and $3347 \mathrm{~cm}^{-1}$ are due to hydrogen-nitrogen stretching as revealed by DFT calculations. After this region, vibrational motion is complex and multiple bonds contribute to the overall vibrational motion of the molecule as shown in the PED analysis in Table 1. The vibrational frequencies in the region 1400 $1625 \mathrm{~cm}^{-1}$ are usually assigned to $\mathrm{C}=\mathrm{C}$ and $\mathrm{C}-\mathrm{C}$ stretching vibrations [25], and with the aid of PED analysis, it is clearly revealed that the vibrations in this range in FTIR and Raman experimental spectra are partially contributed by $\mathrm{C}=\mathrm{C}$ and C-C interactions although there is contribution from other bonds too. Peaks are reasonably in good agreement with DFT values in the region $\left(450-1800 \mathrm{~cm}^{-1}\right)$ both for FTIR 

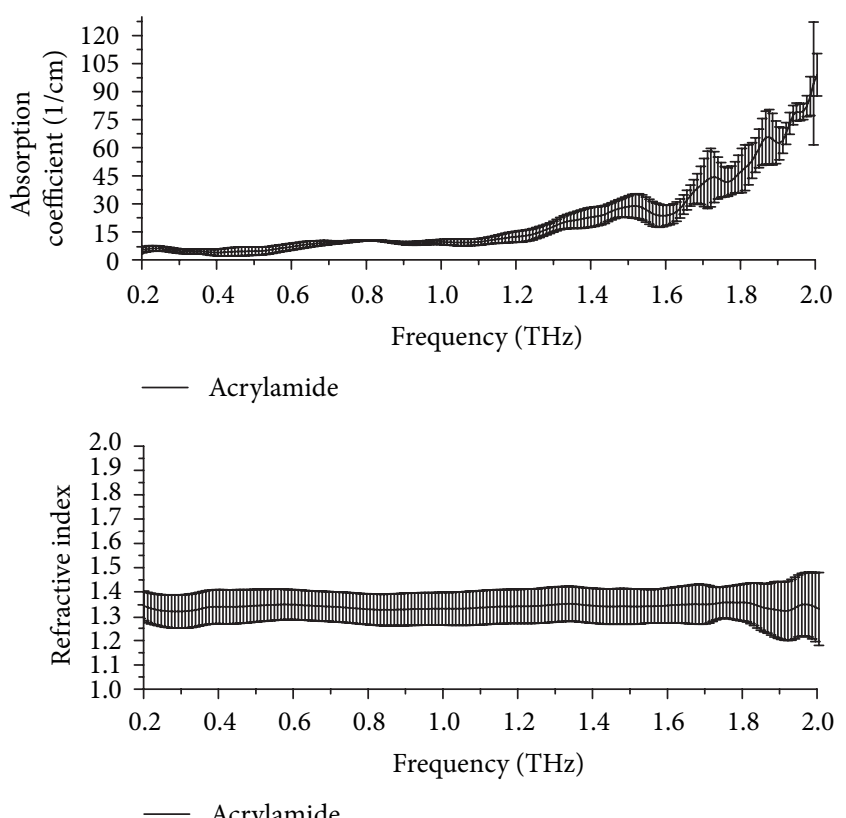

FIGURE 5: Refractive index and absorption coefficient of acrylamide.

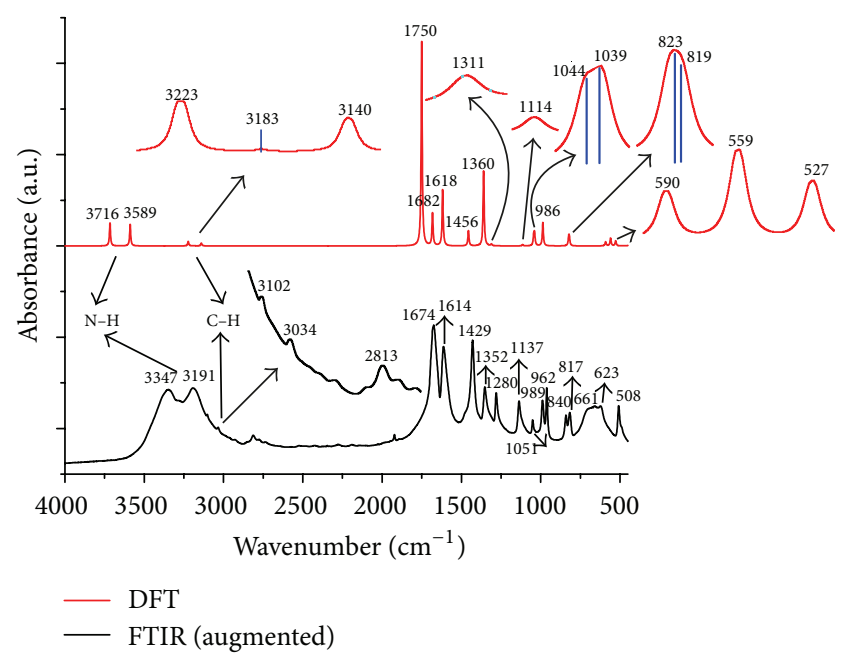

FIGURE 6: FTIR and DFT spectra of Acrylamide, and peaks are marked with their whole number values. See Table 1 for detail.

and Raman after scaling with the scale factor of 0.9679 for vibrational frequencies calculated by Andersson and Uvdal [26]. However, DFT values are deviating over a large extent from experimental values in the $\mathrm{C}-\mathrm{H}$ and $\mathrm{N}-\mathrm{H}$ stretching regions of FTIR even after scaling because of the involvement of intramolecular hydrogen bonding. We use MOLVIB [27, $28]$ to further scale these values and are given in Table 1. PED analysis is also done by MOLVIB. Raman and DFT spectra are shown in Figure 7. Experimental Raman spectrum actually consists of $95-3000 \mathrm{~cm}^{-1}$ range, but because there was no peak after $1800 \mathrm{~cm}^{-1}$ in the experimental Raman spectrum, so graph in Figure 7 is cut off at $2000 \mathrm{~cm}^{-1}$.

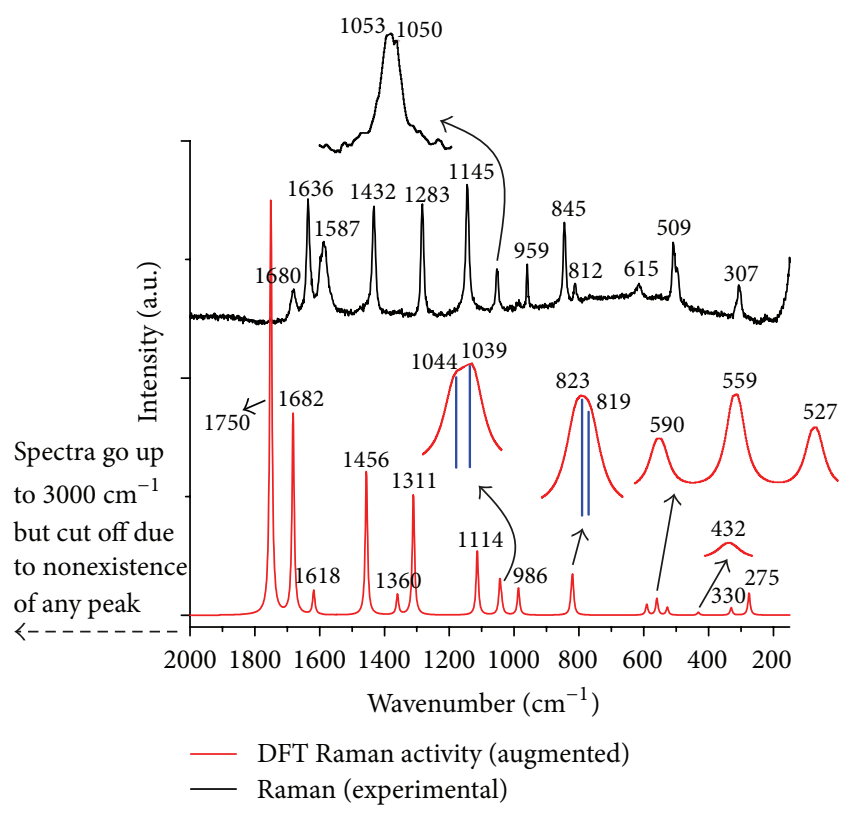

FIGURE 7: Raman and DFT spectra of acrylamide; peaks are marked with their whole number values. See Table 1 for details.

\section{Conclusion}

We have calculated $(0.2-2 \mathrm{THz})$ the relevantly constant refractive index of acrylamide with average value of 1.33 , and absorption coefficient is also constant initially from 0.2 to $1.2 \mathrm{THz}$, and after that it starts rising up exponentially. No absorption peak was observed in the $\mathrm{THz}$ range which is also predicted by DFT calculations according to which first intramolecular vibrational mode appears at $2.78634 \mathrm{THz}$ which is beyond the range of our spectrometer. FTIR (450$4000 \mathrm{~cm}^{-1}$ ) and Raman $\left(95-3000 \mathrm{~cm}^{-1}\right)$ spectra have been presented with different absorption lines and their association with corresponding vibrational modes on the basis of DFT calculations. Scaling was done by MOLVIB to match with the experimental values especially for $\mathrm{C}-\mathrm{H}$ and $\mathrm{N}-\mathrm{H}$ stretching regions.

\section{Acknowledgment}

The authors would like to extend their sincere appreciation to the Deanship of Scientific Research at King Saud University for its funding of this research through the Research Group Project no. RGP-VPP-255.

\section{References}

[1] Y.-S. Lee, Principles of Terahertz Science and Technology, Springer Science+Business Media, 2009.

[2] D. Grischkowsky, S. Keiding, M. van Exter, and Ch. Fattinger, "Far-infrared time-domain spectroscopy with terahertz beams of dielectrics and semiconductors," Journal of the Optical Society of America B, vol. 7, no. 10, pp. 2006-2015, 1990.

[3] R. Piesiewicz, C. Jansen, S. Wietzke, D. Mittleman, M. Koch, and T. Kürner, "Properties of building and plastic materials in the 
THz range," International Journal of Infrared and Millimeter Waves, vol. 28, no. 5, pp. 363-371, 2007.

[4] A. Katsounaros, M. Mann, M. Naftaly, K. Z. Rajab, Y. Hao, and W. I. Milne, "Terahertz time-domain spectroscopy characterization of vertically aligned carbon nanotube films," Carbon, vol. 50, no. 3, pp. 939-942, 2012.

[5] B. Yu, F. Zeng, Y. Yang et al., "Torsional vibrational modes of tryptophan studied by terahertz time-domain spectroscopy," Biophysical Journal, vol. 86, no. 3, pp. 1649-1654, 2004.

[6] J. S. Melinger, S. S. Harsha, N. Laman, and D. Grischkowsky, "Temperature dependent characterization of terahertz vibrations of explosives and related threat materials," Optics Express, vol. 18, no. 26, pp. 27238-27250, 2010.

[7] M. C. Kemp, P. F. Taday, B. E. Cole, J. A. Cluff, A. J. Fitzgerald, and W. R. Tribe, "Security applications of terahertz technology," in Terahertz for Military and Security Applications, vol. 5070 of Proceedings of SPIE, pp. 44-52, April 2003.

[8] J. F. Federici, B. Schulkin, F. Huang et al., "THz imaging and sensing for security applications-explosives, weapons and drugs," Semiconductor Science and Technology, vol. 20, no. 7, pp. S266-S280, 2005.

[9] W. H. Fan, A. Burnett, P. C. Upadhya, J. Cunningham, E. H. Linfield, and A. G. Davies, "Far-infrared spectroscopic characterization of explosives for security applications using broadband terahertz time-domain spectroscopy," Applied Spectroscopy, vol. 61, no. 6, pp. 638-643, 2007.

[10] J. Chen, Y. Chen, H. Zhao, G. J. Bastiaans, and X.-C. Zhang, "Absorption coefficients of selected explosives and related compounds in the range of 0.1-2.8 THz," Optics Express, vol. 15, no. 19, pp. 12060-12067, 2007.

[11] A. Rahman, "Dendrimer based terahertz time-domain spectroscopy and applications in molecular characterization," Journal of Molecular Structure, vol. 1006, no. 1-3, pp. 59-65, 2011.

[12] R. Piesiewicz, T. Kleine-Ostmann, N. Krumbholz et al., "Shortrange ultra-broadband terahertz communications: concepts and perspectives," IEEE Antennas and Propagation Magazine, vol. 49, no. 6, pp. 24-39, 2007.

[13] http://www.who.int/foodsafety/publications/chem/acrylamide_ faqs/en/index.html.

[14] K. M. Wilson, L. A. Mucci, B. A. Rosner, and W. C. Willett, "A prospective study on dietary acrylamide intake and the risk for breast, endometrial, and ovarian cancers," Cancer Epidemiology Biomarkers and Prevention, vol. 19, no. 10, pp. 2503-2515, 2010.

[15] http://www.toptica.com/products/ultrafast_fiber_lasers/femtofiber_pro/femtofiber_pro_nir.html.

[16] http://www.ekspla.com/product/t-spec-series-real-time-terahertz-spectrometer.

[17] http://www.perkinelmer.com/CMSResources/Images/4474804SPC_RamanStation400RRamanStation400F.pdf.

[18] http://www.perkinelmer.com.cn/CMSResources/Images/4674472BRO_Spectrum100FTIR.pdf.

[19] http://www.research.usf.edu/rf/docs/perkin-elmer-spectrum100-ftir-users-guide.pdf.

[20] http://www.reagent.com.cn:666/ScrcBackGroup/reagent/newindex.jsp.

[21] P. D. Cunningham, N. N. Valdes, F. A. Vallejo et al., "Broadband terahertz characterization of the refractive index and absorption of some important polymeric and organic electro-optic materials," Journal of Applied Physics, vol. 109, no. 4, Article ID 043505, 2011.
[22] M. J. Frisch, G. W. Trucks, H. B. Schlegel et al., Gaussian 09, Revision A. 01, Gaussian, Wallingford, Conn, USA, 2009.

[23] V. Rassolov, J. A. Pople, M. Ratner, P. C. Redfern, and L. A. Curtiss, "6-31G* basis set for third-row atoms," Journal of Computational Chemistry, vol. 22, no. 9, pp. 976-984, 2001.

[24] T. Clark, J. Chandrasekhar, G. W. Spitznagel, and P. v. R. Schleyer, "Efficient diffuse function-augmented basis sets for anion calculations. III. The $3-21+\mathrm{G}$ basis set for first-row elements, Li-F," Journal of Computational Chemistry, vol. 4, no. 3, pp. 294-301, 1983.

[25] M. Arivazhagan and R. Meenakshi, "Vibrational spectroscopic studies and DFT calculations of 4-bromo-o-xylene," Spectrochimica Acta Part A, vol. 91, pp. 419-430, 2012.

[26] M. P. Andersson and P. Uvdal, "New scale factors for harmonic vibrational frequencies using the B3LYP density functional method with the triple-zeta basis set 6-311+G(d,p)," Journal of Physical Chemistry A, vol. 109, no. 12, pp. 2937-2941, 2005.

[27] T. Sundius, "Molvib-a flexible program for force field calculations," Journal of Molecular Structure, vol. 218, pp. 321-326, 1990.

[28] T. Sundius, "Scaling of ab initio force fields by MOLVIB," Vibrational Spectroscopy, vol. 29, no. 1-2, pp. 89-95, 2002. 

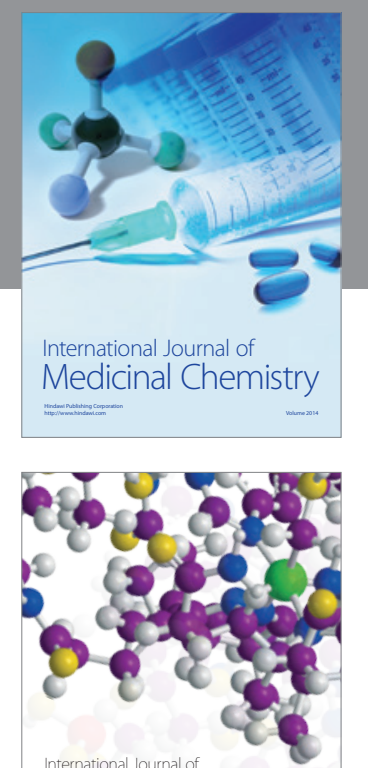

\section{Carbohydrate} Chemistry

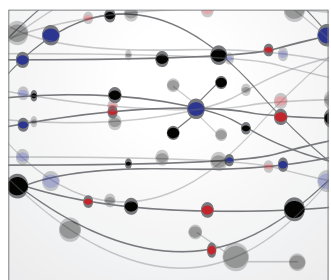

The Scientific World Journal
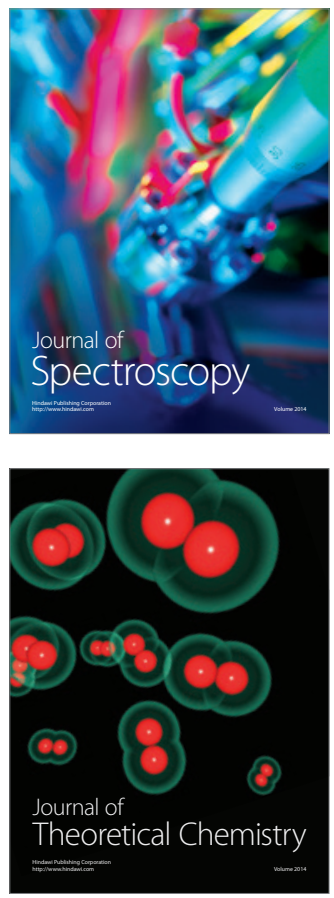
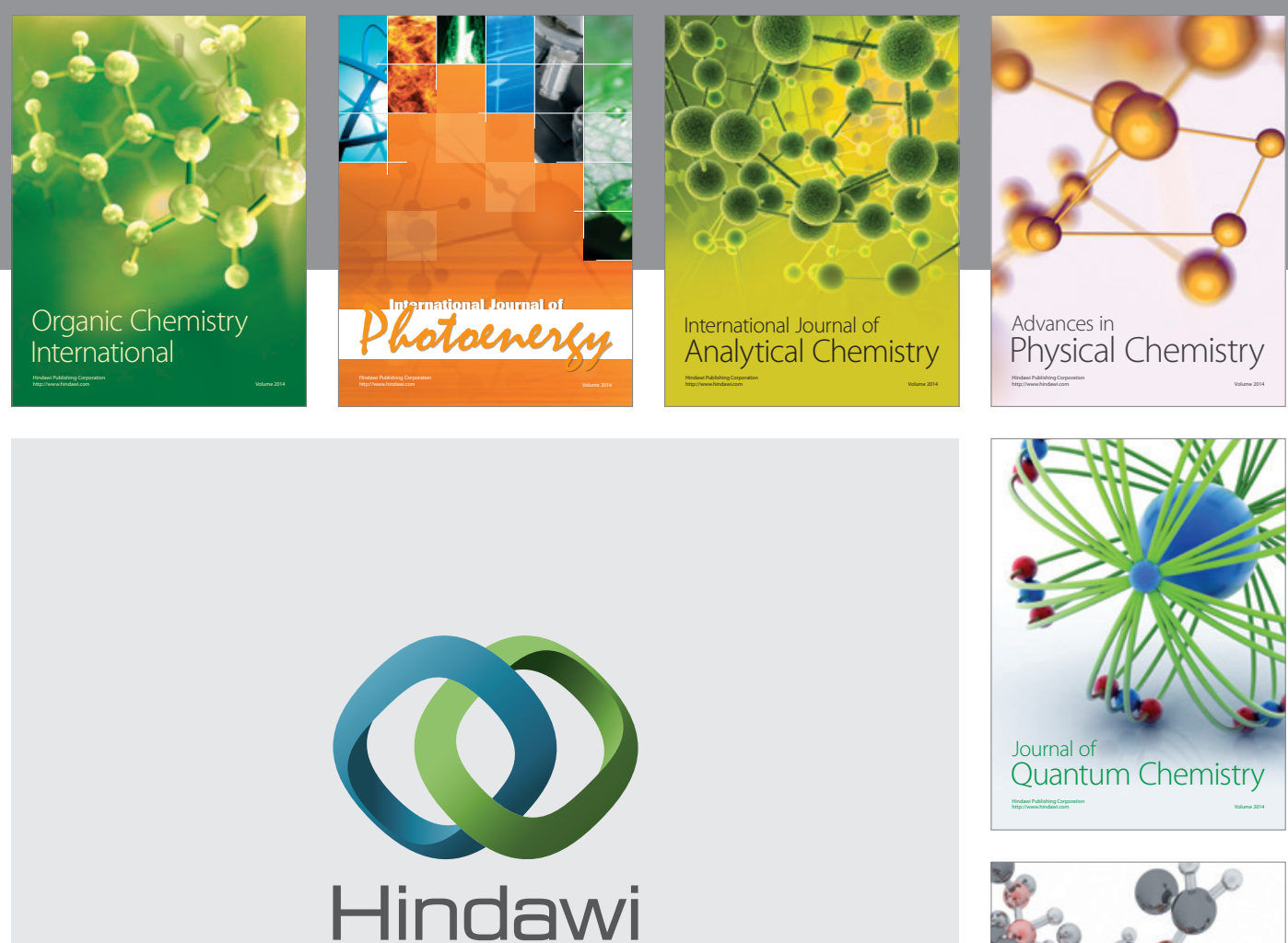

Submit your manuscripts at

http://www.hindawi.com

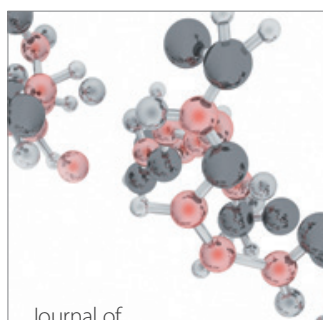

Analytical Methods

in Chemistry

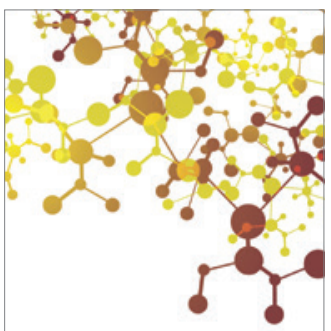

Journal of

Applied Chemistry

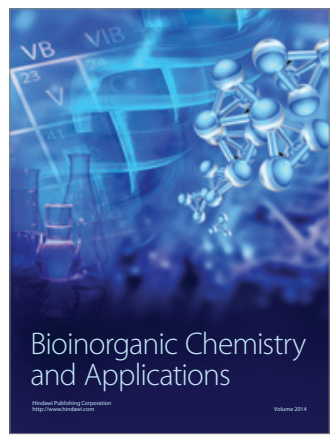

Inorganic Chemistry
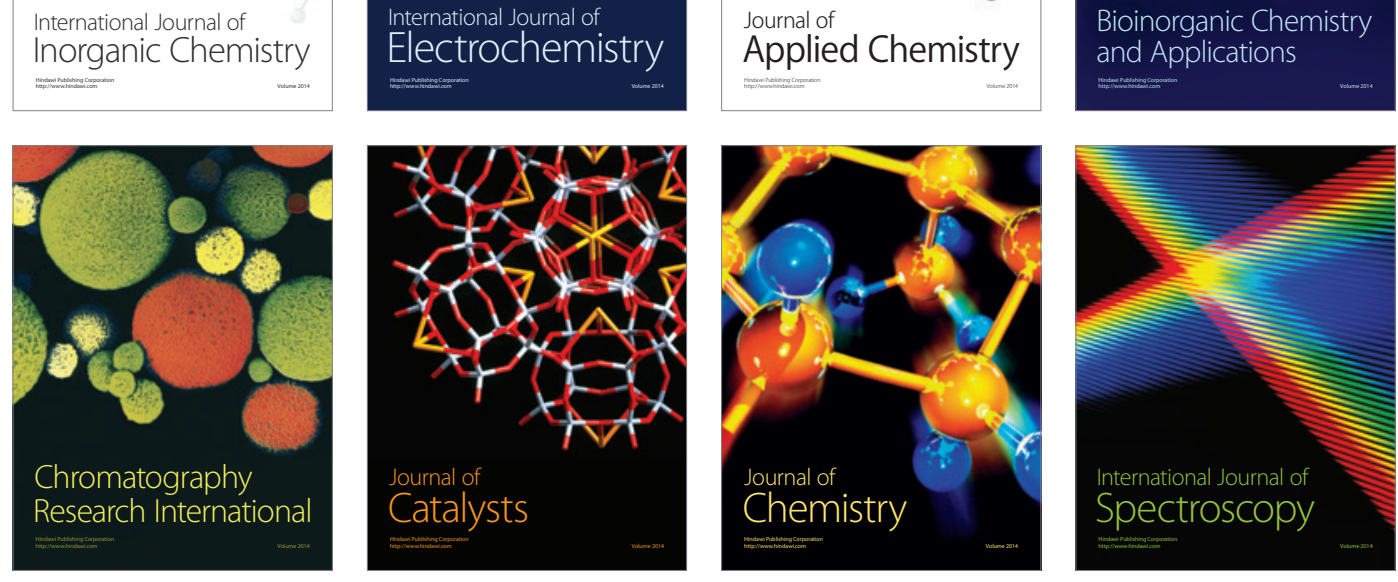